DOI: $10.5455 / 2320-1770.1 j \operatorname{rcog} 20140955$

Case Report

\title{
Successful outcome in a patient with glioma of brain with twin pregnancy
}

\section{Anjali Rani*, Prashanta Krishna Gupta}

\begin{abstract}
Department of Obstetrics \& Gynecology, Institute of Medical Sciences, Banaras Hindu University, Varanasi-221005,
\end{abstract} Uttar Pradesh, India

Received: 16 July 2014, Revised: 26 July 2014

Accepted: 8 August 2014

\section{*Correspondence:}

Dr. Anjali Rani,

E-mail: anjaliraniimsbhu@gmail.com

(C) 2014 Rani A et al. This is an open-access article distributed under the terms of the Creative Commons Attribution Non-Commercial License, which permits unrestricted non-commercial use, distribution, and reproduction in any medium, provided the original work is properly cited.

\begin{abstract}
We present a case of glioma in pregnant female with twin pregnancy. Gliomas during pregnancy are rare. Gliomas during pregnancy pose a risk to maternal and fetal life. The benefit-to-risk ratio should be carefully evaluated and discussed prior to get marriage and pregnancy. In present case, patient had non-specific symptom like seizure and no any focal neurological deficit, Caesarean Section (CS) was done at term with multidisciplinary group, including a neurosurgeon, obstetrician, anesthesiologist and neonatologist. She has been followed up to the present date and remains in good health.
\end{abstract}

Keywords: Glioma of brain, Twin pregnancy

\section{INTRODUCTION}

Gliomas during pregnancy are rare. Primary CNS tumors occur in 6 in 100000 females but are rare in pregnanc. ${ }^{1}$ It is non-obstetrical cause of maternal mortality and morbidity. Normally these patients are advised not to become pregnant. In gliomas maternal mortality and morbidity increases because of its complications arises due to increase intracranial pressure. In this patient it was low grade glioma and was asymptomatic so "watch and wait" policy was observed.

\section{CASE REPORT}

27 years old booked female, primigravida with height of $160 \mathrm{~cm}$ and Wight of $66 \mathrm{~kg}$, presented with eight and half month amenorrhea with twin pregnancy admitted for safe confinement. On examination vitals was normal.

Per abdomen examination showed uterine size more than date with presence of two fetal pole, twin-1 cephalic, twin-2 breech, relaxed, and presence of two regular F.H.S 140 at two different places. She was MRI diagnosed case of low grade glioma of brain 2 years back. She had minimal symptoms like seizure and headache and kept on antiepileptic drugs (phenytoin). The prognosis of glioma was discussed and advised not to get married and pregnant but she came in OPD with pregnancy and got registered She was explained regarding risk-benefit for continuation of pregnancy but she continued pregnancy with changing of safer antiepileptic drug in pregnancy.

MRI report showed large ill-defined mass lesion in left temporal lobe $(7.4 \times 6.1 \times 4.7 \mathrm{~cm})$ with involvement of left insular cortex, adjacent left basal ganglia (Figure 1, 2, 3).

She planed elective caesarean with consultation of neurosurgery, and anesthesiology departments under general anesthesia with coverage of injectable antiepileptics and antibiotic. twin-1 male $1900 \mathrm{~g}$ and twin-2 male, $1700 \mathrm{gm}$ were delivered $6 \mathrm{~min}$ after the skin incision with APGAR's score of neonates are 8 and 9 in $1^{\text {st }}$ and $5^{\text {th }}$ minute. Per-op and post op period was uneventful. Patient was discharged on post-op day- 8 with regular follow up in neurosurgery OPD. 


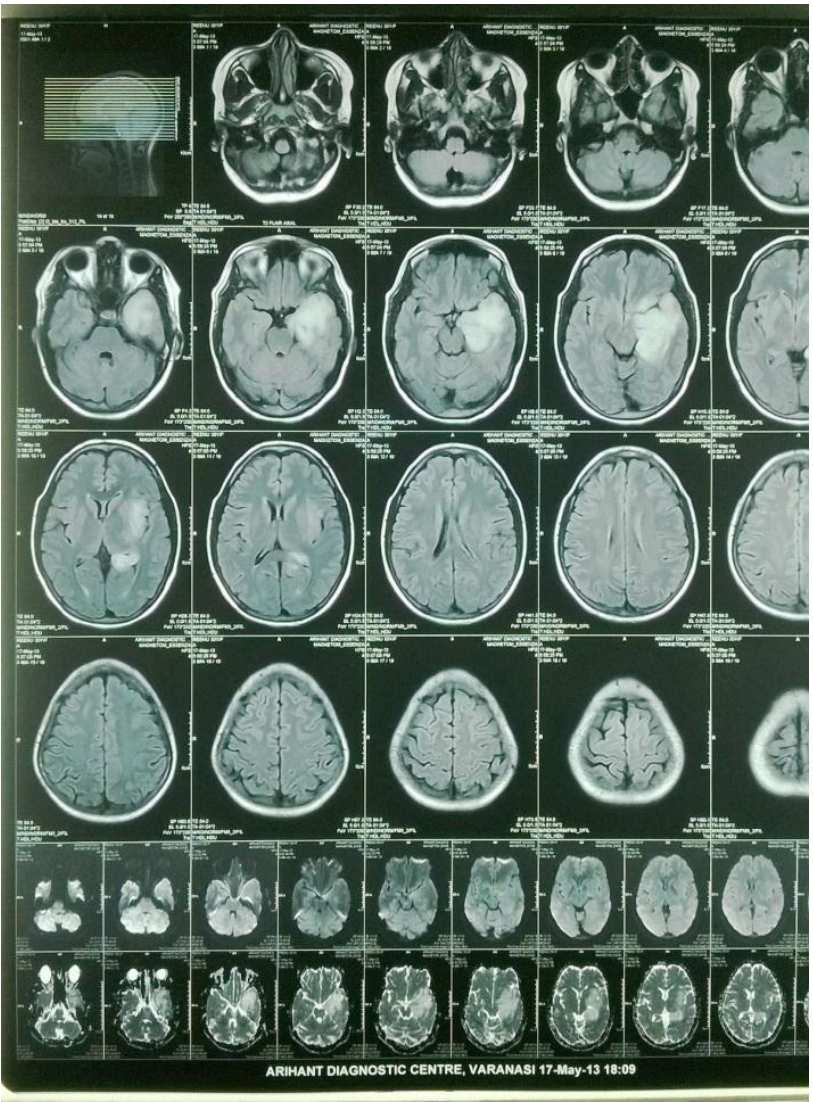

Figure 1: MRI showing glioma of brain.

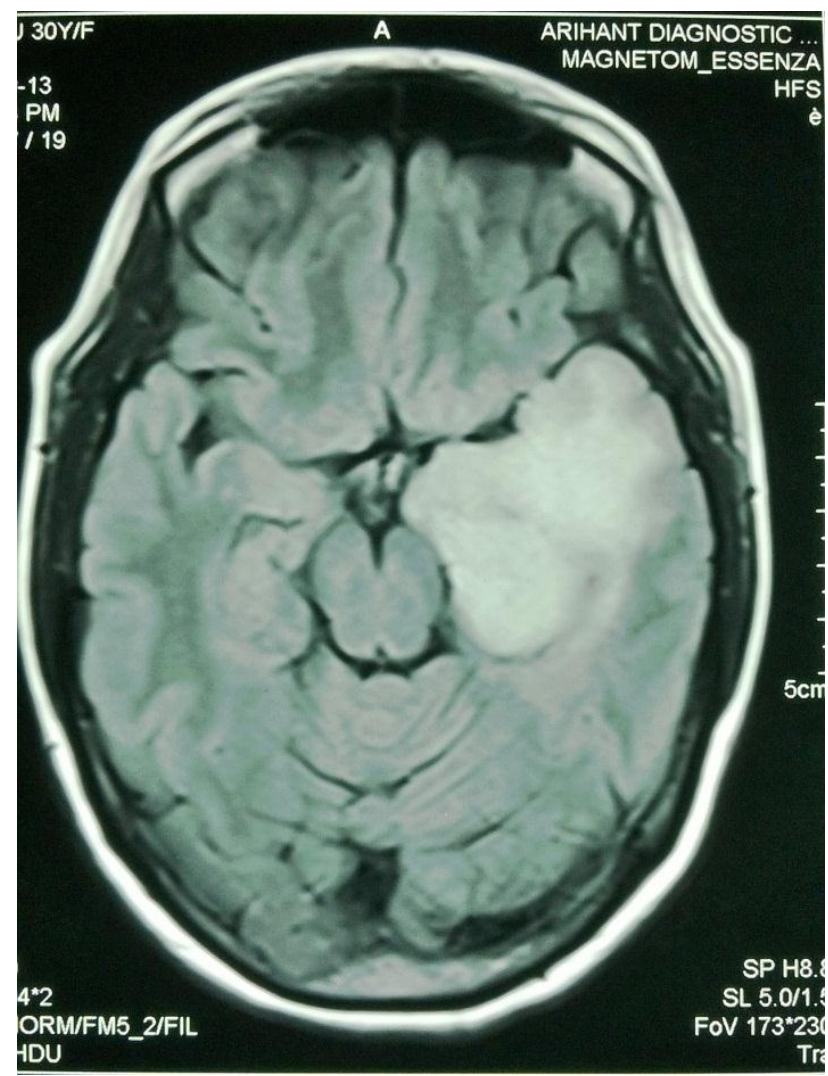

Figure 2: Shows glioma situated in temporal lobe.

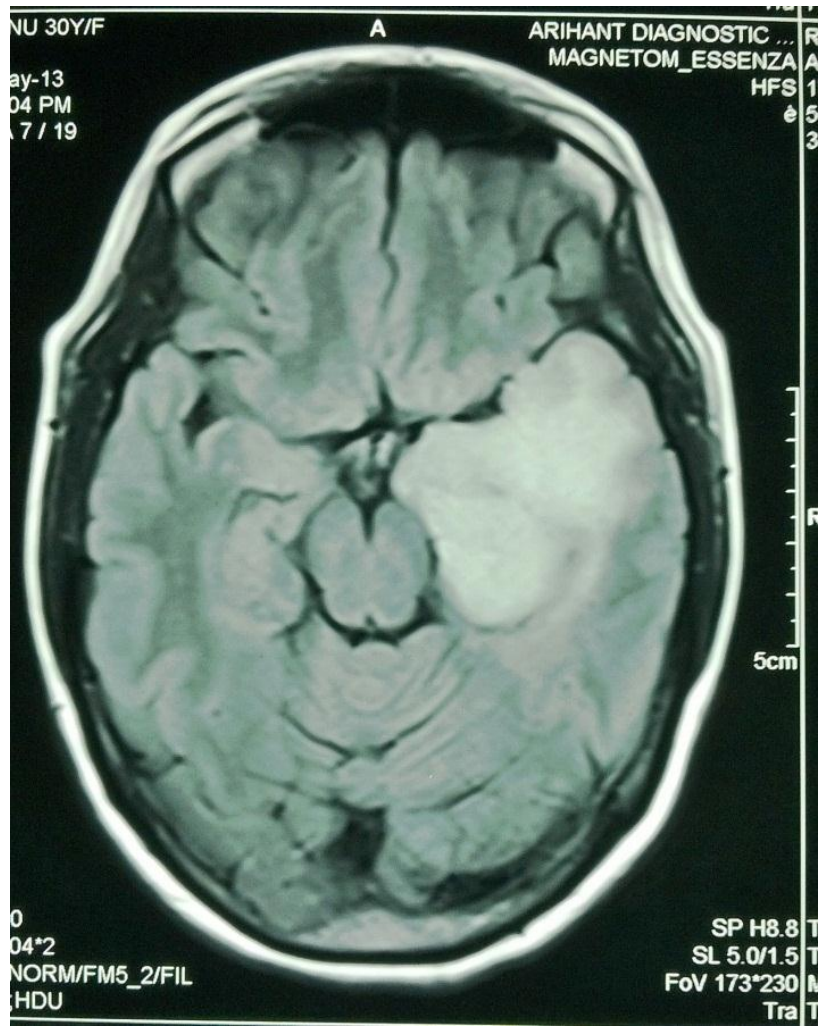

Figure 3: Shows glioma situated in temporal lobe.

\section{DISCUSSION}

Under the recent World Health Organization classification of primary intracranial tumours, low grade glioma would encompass grade I and grade II neuroepithelial tumours. The more common grade I tumours are pilocytic astrocytoma, Dysembryoblastic NeuroEpithelial Tumours (DNET), Pleomorphic XanthoAstrocytoma (PXA), neurocytoma, and ganglioglioma. The more common grade II tumours include astrocytoma, oligodendroglioma, and mixed oligoastrocytoma. This spectrum of discreet neuropathological entities is important since the grade I tumours generally can be cured by surgical excision and their symptoms very often alleviated. conversely, with the grade II tumours, these are generally incurable but have median survival times of $>5$ years. $^{2-4}$ Tumours with oligodendodrial components generally do better than astrocytomas, with prognosis being partially related to gene deletions on chromosome $1 \mathrm{p}$ and $19 \mathrm{q} .{ }^{5-6}$ Some grade II gliomas are "diffuse" while others have relatively well defined brain-tumour interfaces.

While the median age of symptom onset is 35 years with grade II lesions, grade I lesions usually present at a younger age. The most common $(80 \%)$ presentation of a "low grade glioma" is with seizure disorders. This is particularly common with temporal, insular, frontal, and peri-rolandic lesions. Because in general these tumours displace or infiltrate the brain without destroying the neuropil, focal neurological deficits are uncommon. 
Conventional strategies in neuro-oncology consist of surgery, radiotherapy, and chemotherapy. ${ }^{1-4,6,7-9}$ In addition, however, with low grade gliomas, because of the advent of MRI scanning, a "watch and wait" policy can be appropriate on occasions. ${ }^{2,3,6}$

Pregnancy induces major changes in maternal hormones. Possibly the enhanced growth rate of glioma tumors is related to the activation of specific receptors by these hormones. For instance progesterone enhances cell growth in human gliomas ${ }^{10}$ Further, secretion of placental growth hormone at the maternal-placental interface stimulates secretion of growth factors. ${ }^{11}$ Insulin-like growth factors strongly stimulate glioma cell migration and glioma growth1.,13 The rare emergence of contrast enhancement during pregnancy may be linked to the antiangiogenic effects of progesterone and other growth factors that regulate maternal responses to a growing foetus $1^{4,15}$ and may balance proangiogenic effects of placental growth factors. ${ }^{16}$

A multidisciplinary team recommends the optimal timing for the termination of pregnancy, as determined by the fetus maturity and mother's neurological condition. The various treatment modalities in pregnant women with glioma are associated with histology and gestational age. $^{17}$

Delivery by CS followed by neurosurgery is almost always performed under general anesthesia. Studies have shown that general anesthesia is safe and well tolerated for neuro-anesthesia during pregnancy. ${ }^{18}$ Airway management must address the avoidance of increases in intracranial pressure, the presence of a potentially full stomach, pregnancy-induced changes to the airway and enlarged breasts, which increase the incidence of a difficult intubation. ${ }^{19}$ It is important to preserve cerebral and uteroplacental perfusion by maintaining hemodynamic stability. Extubation should be delayed until the patient is sufficiently awake for the patient's airway to be protected from regurgitation and pulmonary aspiration. The postoperative management of pregnant patients following neurosurgical intervention is similar to that of non-pregnant patients.

Funding: No funding sources Conflict of interest: None declared

Ethical approval: Not required

\section{REFERENCES}

1. Chang L, Looi-Lyons L, Bartosik L, Tindal S. Anesthesia for cesarean section in two patients with brain tumours. Can J Anesth. 1999;46:61-5.

2. Keles GE, Lamborn KR, Berger MS. Low-grade hemispheric gliomas in adults: a critical review of extent of resection as a factor influencing outcome. $\mathrm{J}$ Neurosurg. 2001;95:735-45.

3. Wilson CB, Bramwell V, Bonfill X, Cuzick J, Grant $\mathrm{R}$, Guthrie D, et al. Central nervous system tumours.
In: Williams CB, eds. Evidence-Based Oncology. London: BMJ Books; 2003: 561-564.

4. Wessels PH, Weber WEJ, Raven G, Ramaekers FCS, Hopman AHN, Twijnstra A. Supratentorial grade II astrocytoma: biological features and clinical course. Lancet Neurol. 2003;2:395-403.

5. Ellis TL, Stieber VW, Austin RC. Oligodendroglioma. Curr Treat Options Oncol. 2003;4:479-90.

6. Feigenberg SJ, Amdur RJ, Morris CG, Mendenhall WM, Marcus RB Jr, Friedman WA. Oligodendroglioma: does deferring treatment compromise outcome? Am J Clin Pathol. 2003;26:e60-6.

7. Lang FF, Olansen NE, DeMonte F, Gokaslan ZL, Holland EC, Kalhorn C, et al. Surgical resection of intrinsic insular tumors: complication avoidance. J Neurosurg. 2001;95:638-50.

8. Duffau H, Capelle L, Denvil D, Sichez N, Gatignol $\mathrm{P}$, Lopes M, et al. Functional recovery after surgical resection of low grade gliomas in eloquent brain: hypothesis of brain compensation. J Neurol Neurosurg Psychiatry. 2003;74:901-7.

9. Peraud A, Meschede M, Eisner W, Ilmberger J, Reulen HJ. Surgical resection of grade II astrocytomas in the superior frontal gyrus. Neurosurgery. 2002;50:966-75.

10. Gonzalez-Aguero G, Gutierrez AA, GonzalezEspinosa D, Solano JD, Morales R, González-Arenas A, et al. Progesterone effects on cell growth of U373 and D54 human astrocytoma cell lines. Endocrine. 2007;32:129-35.

11. Fuglsang J, Ovesen P. Aspects of placental growth hormone physiology. Growth Horm IGF Res. 2006; 16:67-85.

12. Jiang W, Xiang C, Cazacu S, Brodie C, Mikkelsen T. Insulin-like growth factor binding protein 7 mediates glioma cell growth and migration. Neoplasia. 2008;10:1335-42.

13. Schlenska-Lange A, Knupfer H, Lange TJ, Kiess W, Knüpfer M. Cell proliferation and migration in glioblastoma multiforme cell lines are influenced by insulin-like growth factor I in vitro. Anticancer Res. 2008;28:1055-60.

14. Bengtson NW, Linzer DI. Inhibition of tumor growth by the antiangiogenic placental hormone, proliferinrelated protein. Mol Endocrinol. 2000;14:1934-43.

15. Rao BR. Pregnancy associated highly vascularized tumours negatively correlate with the levels of antiangiogenic $17 \quad$ alpha-hydroxyprogesterone Anticancer Res. 1997;17:1019-21.

16. Adini A, Kornaga T, Firoozbakht F, Benjamin LE. Placental growth factor is a survival factor for tumor endothelial cells and macrophages. Cancer Res. 2002;62:2749-52.

17. Ducray F, Colin P, Cartalat-Carel S, PelissouGuyotat I, Mahla K, Audra P, et al. Management of malignant gliomas diagnosed during pregnancy. Rev Neurol (Paris). 2006;162:322-9. 
18. Goldschlager T, Steyn M, Loh V, Selvanathan S, Vonau M, Campbell S. Simultaneous craniotomy and caesarean section for trauma. $\mathrm{J}$ Trauma. 2009;66:E50-1.

19. Stupp R, Mason WP, van den Bent MJ, Weller M, Fisher B, Taphoorn MJ, et al. Radiotherapy plus concomitant and adjuvant temozolomide for glioblastoma. N Engl J Med. 2005;352:987-96.

DOI: $10.5455 / 2320-1770$. ijrcog20140955

Cite this article as: Rani A, Gupta PK. Successful outcome in a patient with glioma of brain with twin pregnancy. Int J Reprod Contracept Obstet Gynecol 2014;3:827-30. 